\title{
Involvement of adiponectin and leptin in breast cancer: clinical and in vitro studies
}

\author{
T Jardé1, F Caldefie-Chézet ${ }^{1}$, N Goncalves-Mendes ${ }^{1}$, F Mishellany ${ }^{2}$, \\ C Buechler ${ }^{3}, F$ Penault-Llorca ${ }^{2}$ and M P Vasson ${ }^{1,4}$
}

\author{
${ }^{1}$ Université Clermont 1, UFR Pharmacie, EA4233, CLARA, CRNH-A, 63001 Clermont-Ferrand, France \\ ${ }^{2}$ Centre Jean-Perrin, Laboratoire d'Anatomopathologie, 63000 Clermont-Ferrand, France \\ ${ }^{3}$ Université de Regensburg, Département de Médecine Interne I, 93042 Regensburg, Germany \\ ${ }^{4}$ Centre Jean-Perrin, Unité de Nutrition, 63000 Clermont-Ferrand, France \\ (Correspondence should be addressed to T Jardé; Email: jardethierry@yahoo.fr)
}

\begin{abstract}
Obesity is a risk factor for breast cancer development. A recent hypothesis suggests that the adipokines, adiponectin and leptin, are involved in breast cancer development. This prompted us to investigate the role of adiponectin and leptin in mammary carcinogenesis. Adiponectin receptors (AdipoR1 and AdipoR2) and leptin receptor (Ob-Rt, representing all the isoforms of $\mathrm{Ob}-\mathrm{R})$ proteins were detected by immunohistochemistry in in situ ductal carcinoma, invasive ductal malignancy, and healthy adjacent tissue. In addition, mRNA expression of adiponectin, AdipoR1, AdipoR2, leptin, Ob-Rt, and Ob-RI (the long isoform of Ob-R) was observed in MCF-7 breast cancer cells. Interestingly, leptin mRNA expression was 34.7-fold higher than adiponectin mRNA expression in the MCF-7 cell line. Moreover, adiponectin $(10 \mu \mathrm{g} / \mathrm{ml})$ tended to decrease the mRNA expression of leptin $(-36 \%)$ and Ob-RI $(-28 \%)$ and significantly decreased Ob-Rt mRNA level $(-26 \%)$. In contrast, leptin treatment $(1 \mu \mathrm{g} / \mathrm{ml})$ significantly decreased AdipoR1 mRNA (-23\%). Adiponectin treatment $(10 \mu \mathrm{g} / \mathrm{ml})$ inhibited the proliferation of MCF-7 cells, whereas leptin $(1 \mu \mathrm{g} / \mathrm{ml})$ stimulated the growth of cancer cells. In addition, adiponectin inhibited leptin-induced cell proliferation (both $1 \mu \mathrm{g} / \mathrm{ml}$ ). Using microarray analysis, we found that adiponectin reduced the mRNA levels of genes involved in cell cycle regulation (mitogen-activated protein kinase 3 and ATM), apoptosis (BAG1, BAG3, and TP53), and potential diagnosis/prognosis markers (ACADS, CYP19A1, DEGS1, and EVL), whereas leptin induced progesterone receptor mRNA expression. In conclusion, the current study indicates an interaction of leptin- and adiponectin-signaling pathways in MCF-7 cancer cells whose proliferation is stimulated by leptin and suppressed by adiponectin.
\end{abstract}

Endocrine-Related Cancer (2009) 16 1197-1210

\section{Introduction}

Obesity is related to many metabolic disorders like type 2 diabetes mellitus, coronary heart disease, and hypertension, and is notably associated with an increased risk for breast cancer in postmenopausal women (Klein et al. 2002). Numerous factors (obesityassociated hyperinsulinemia and high adipose tissueinduced estrogen levels) have been suggested to explain the relationship between obesity and breast cancer, but none have been totally conclusive. Adipose cells were initially considered as a fat-storing tissue but are now known to have much more complex and dynamic functions, notably acting as an endocrine organ secreting a range of adipokines, including adiponectin and leptin.

Adiponectin is a 224 amino acid-long polypeptide with several metabolic activities, including antidiabetic, anti-inflammatory, and anti-atherogenic properties (Maeda et al. 1996, Kershaw \& Flier 2004). This cytokine is the most abundant protein synthesized by adipose cells, with plasma concentrations ranging from 2 to $30 \mu \mathrm{g} / \mathrm{ml}$ (Maeda et al. 1996). Paradoxically, obese subjects present strongly decreased levels of circulating adiponectin 
(Arita et al. 1999, Matsubara et al. 2002). Leptin is a $16 \mathrm{kDa}$ polypeptide hormone encoded by the obese gene (Zhang et al. 1994) that is involved in the regulation of energy balance (De Vos et al. 1995), reproduction, and immunity (Mounzih et al. 1997, Caldefie-Chezet et al. 2003), and acts as a proinflammatory factor (Lago et al. 2007). Despite the numerous nonadipose sources described (Mix et al. 2000, Solberg et al. 2005), the main source of leptin in the body remains adipose tissue. In stark contrast with adiponectin, plasma leptin concentration increases with body mass index (Ruhl \& Everhart 2001).

Current hypotheses suggest that adiponectin and leptin could play a role in breast cancer development. Several studies have demonstrated that low serum adiponectin levels and high serum leptin levels are associated with increased risk for breast cancer (Miyoshi et al. 2003, Mantzoros et al. 2004, Han et al. 2005, Chen et al. 2006b). Furthermore, Chen et al. (2006b) reported that the ratio between serum leptin and serum adiponectin correlated positively with tumor size.

To date, only two studies have examined the expression of adiponectin and its receptors (AdipoR1 and AdipoR2) in breast cancer biopsies. Takahata et al. (2007) observed that adiponectin mRNA was not expressed in breast tumor tissue or in breast cancer cell lines, whereas AdipoR1 and AdipoR2 mRNAs were both expressed. Korner et al. (2007) reported that AdipoR1 and AdipoR2 proteins were detected in 30.4 and $26.3 \%$ of breast cancer biopsies respectively. In previous studies, we demonstrated that leptin and leptin receptor (Ob-Rt) were involved in breast cancer, since both markers were expressed in mammary tumor (Caldefie-Chezet et al. 2005, Jarde et al. 2008a).

Numerous in vitro studies have explored the involvement of adipokines in breast cancer. Adiponectin has been shown to mediate an anti-proliferative response, while leptin enhances proliferation in MCF7, MDA-MB-231, SK-BR-3, and T47D breast cancer cells (Dieudonne et al. 2002, 2006, Hu et al. 2002, Kang et al. 2005, Korner et al. 2007, Ray et al. 2007, Grossmann et al. 2008). The activities of both adiponectin and leptin in breast cancer cell growth are in part mediated by cell cycle inhibition or stimulation respectively, (Nakayama et al. 2007, Saxena et al. 2007) and by the induction of apoptosis or downregulation of pro-apoptotic p53 mRNA respectively (Chen et al. 2006a, Dieudonne et al. 2006).

In order to better understand the potential involvement of these two adipokines in breast cancer, we investigated the expression of adiponectin and leptin receptors in biopsies of different grades of epithelial ductal breast lesions and adjacent normal tissue. We also evaluated in vitro the effect of adiponectin, leptin, or both on breast cancer cell proliferation, on the adiponectin and leptin pathways, and on the expression of molecular markers used to diagnose and gauge prognosis of breast cancer.

\section{Materials and methods}

\section{Clinical study on breast cancer biopsies}

\section{Breast cancer biopsies}

A total of 45 breast cancer tissue samples from women not treated by radiotherapy or chemotherapy were obtained from the tumor bank at the Jean-Perrin Anti-Cancer Center (Clermont-Ferrand, France). Primary breast cancer tissue samples were fixed in alcohol-formalin-acetic acid and embedded in paraffin.

\section{Tissue classification}

Diagnoses were made on paraffin-embedded $4 \mu \mathrm{m}$ tissue sections after hematoxylin-eosin-saffron staining. Tissues were classified according to histological subtypes as malignant lesions corresponding to in situ ductal carcinoma $(n=14)$ or invasive ductal carcinoma of different grades $(n=45)$. Invasive tumors were evaluated according to the SBR grade classification modified by Elston \& Ellis (1991). Normal tissue adjacent to breast cancer was also analyzed $(n=40)$.

\section{Immunohistochemistry}

AdipoR1, AdipoR2, and Ob-Rt protein expression was investigated by immunohistochemical staining using affinity-purified polyclonal biotinylated antibodies raised against AdipoR1 (Phoenix Pharmaceuticals, Burlingame, CA, USA), AdipoR2 (Phoenix Pharmaceuticals), and Ob-Rt (recognizing all six isoforms of Ob-R; Roche).

Sections were deparaffinated in xylene and rehydrated in graded alcohols. Antigen retrieval was performed for AdipoR1 and AdipoR2 localization. The immunohistochemical procedure was performed as previously described (Jarde et al. 2008a).

\section{Microscopic examination}

The immunostaining was assessed by a pathologist blinded to the clinical data. AdipoR1, AdipoR2, and Ob-Rt expression in tumor and normal adjacent tissues was classified as either negative ( $<5 \%$ labeled cells) or positive ( $\geq 5 \%$ labeled cells). Expression intensity was graded as 0 (none), $1+$ (mild), $2+$ (moderate), or $3+$ (intense). 


\section{In vitro studies}

\section{Cell culture}

The human breast cancer cell line MCF-7 was obtained from the American Type Culture Collection (ATCC). These cells were routinely cultured in a phenolred-free RPMI 1640 medium supplemented with $10 \%$ heat-inactivated FCS, L-glutamine $(2 \mathrm{mM})$, and gentamicin $(50 \mu \mathrm{g} / \mathrm{ml})$ at $37{ }^{\circ} \mathrm{C}$ under $5 \% \mathrm{CO}_{2}$ atmosphere.

\section{Immunohistochemistry}

MCF-7 cells were grown on plastic slides for $48 \mathrm{~h}$ in a $37^{\circ} \mathrm{C}$ humidified atmosphere under $5 \% \mathrm{CO}_{2}$ before fixing with acetone for $10 \mathrm{~min}$. Immunohistochemical detection of AdipoR1, AdipoR2, and Ob-Rt proteins was performed as described above.

\section{Proliferation assay}

MCF-7 cells were plated at a density of $5 \times 10^{3}$ cells in 96-well plates in a complete medium, and were allowed to adhere in an incubator. After $48 \mathrm{~h}$, cells were washed with PBS and exposed to fresh medium containing 5\% heat-inactivated FCS with full-length human trimeric adiponectin at $0.1,1$ (obese concentration), and $10 \mu \mathrm{g} / \mathrm{ml}$ (physiological concentration; Neumeier et al. 2006), with human recombinant leptin (Roche) at 0.01 (physiological concentration), 0.1 (obese concentration), and $1 \mu \mathrm{g} / \mathrm{ml}$, or both, adiponectin and leptin $(1 \mu \mathrm{g} / \mathrm{ml}$ each). The percentage of FCS in the medium was reduced to minimize the effect of other growth factors on breast cancer cells. After 24, 48, 72, and $96 \mathrm{~h}$, cells were washed with PBS and $200 \mu \mathrm{l}$ of a $25 \mu \mathrm{g} / \mathrm{ml}$ solution of resazurin in RPMI 1640 medium were added to each well. The plates were incubated for $2 \mathrm{~h}$ at $37^{\circ} \mathrm{C}$ in a humidified atmosphere containing $5 \% \mathrm{CO}_{2}$. Fluorescence was then measured on an automated 96-well plate reader (Fluoroskan Ascent FL, Thermo Fisher Scientific, Wilmington, DE, USA) using an excitation wavelength of $530 \mathrm{~nm}$ and an emission wavelength of $590 \mathrm{~nm}$. Under these conditions, fluorescence was proportional to the number of living cells in the well (Debiton et al. 2003). The cell proliferation assay was performed five times in replicates of six wells for each concentration tested.

\section{Microarray analysis}

MCF-7 cells were exposed to adiponectin $(10 \mu \mathrm{g} / \mathrm{ml})$ or leptin $(1 \mu \mathrm{g} / \mathrm{ml})$ for $96 \mathrm{~h}$ as described above. Total RNA was extracted using TRIzol according to the manufacturer's guidelines (Invitrogen). The quality and quantity of total RNA were evaluated by measuring the A260/A280 ratio (at least 1.9) using a NanoDrop 8000 spectrophotometer (Thermo Fisher
Scientific) coupled with gel electrophoresis. Using the TrueLabeling-AMP 2.0 kit (Superarray, Frederick, MD, USA), the mRNAs were reverse transcribed into cDNA and converted by transcription to obtain biotin-labeled cRNA using biotin-16-UTP (Roche). The biotinylated cRNA probes were purified with the ArrayGrade cRNA cleanup kit (Superarray) and then hybridized overnight to the pretreated Oligo GEArray Human Breast Cancer Biomarker Microarray (Superarray), which profiles the expression of 264 genes that are considered useful molecular markers in the diagnosis and prognosis of breast cancer. Following several washing steps, biotinylated cRNA probes hybridized to the array were detected by a Chemiluminescent Detection kit (Superarray), using alkaline phosphatase-conjugated streptavidin and CDP-Star as chemiluminescent substrate. Chemiluminescence was detected on a CCD camera Versadoc Imaging System (Bio-Rad Laboratories). Data acquisition and quantification of spot intensities were performed using GEArray Expression Analysis Suite 2.0 software (Superarray). Data evaluation included background correction (subtraction of minimum value) and housekeeping gene normalization. Each determination corresponds to the mean value \pm s.D. of four independent assays to ensure reproducibility of the results. Only genes whose expression changed similarly in all four comparative analyses were considered adipokineresponsive genes $(P<0.1$, statistical trend; $P<0.05$, significant difference, $t$-test), as previously described (Le Corre et al. 2006).

\section{Quantitative RT-PCR}

The GEArray results were validated by confirming the adipokine-induced modification of gene expression using quantitative reverse transcription-PCR (qRT-PCR). We also investigated the effect of adiponectin and leptin on selected genes (adiponectin, leptin, AdipoR1, AdipoR2, Ob-Rt, and Ob-Rl), which were not spotted on microarrays.

RT was conducted from $1 \mu \mathrm{g}$ total RNA (extracted for GEArray analysis), yielding $20 \mu \mathrm{l}$ cDNA as previously described (Goncalves-Mendes et al. 2004). The cDNAs were amplified using the primers summarized in Table 1. The qPCR was performed using Light Cycler Fast Start DNA Master SYBR Green I following the manufacturer's instructions, on a LightCycler Instrument (Roche Diagnostics). Sample mRNA copy numbers were extrapolated from standard curves obtained with serially diluted purified PCR products. The real-time qPCR program was $50{ }^{\circ} \mathrm{C}$ for $2 \mathrm{~min}, 95^{\circ} \mathrm{C}$ for $10 \mathrm{~min}$, and 50 cycles of $95^{\circ} \mathrm{C}$ for $15 \mathrm{~s}$ 
$T$ Jardé et al.: Adiponectin, leptin, and breast cancer

Table 1 Primers used in quantitative reverse transcription-PCR assays

\begin{tabular}{|c|c|c|}
\hline \multirow[b]{2}{*}{ Gene } & \multicolumn{2}{|c|}{ Sequence } \\
\hline & Forward & Reverse \\
\hline Adiponectin & 5'-ATGGTCCTGTGATGCTTTGA-3' & 5'-GAGAGTAAATGCACCAATAAG-3' \\
\hline Leptin & 5'-TGAGCACCTGCTTCATGCTC-3' & 5'-TGAGTGCGGTTTGACCACTG-3' \\
\hline AdipoR1 & 5'-AATTCCTGAGCGCTTCTTTCCT-3' & 5'-CATAGAAGTGGACAAAGGCTGC-3' \\
\hline AdipoR2 & 5'-TGCAGCCATTATAGTCTCCCAG-3' & 5'-GAATGATTCCACTCAGGCCTAG-3' \\
\hline OB-Rt & 5'-CATTTTATCCCCATTGAGAAGTA-3' & 5'-CTGAAAATTAAGTCCTTGTGCCCAG-3' \\
\hline $\mathrm{Ob}-\mathrm{Rl}$ & 5'-GATAGAGGCCCAGGCATTTTTTA-3' & 5'-ACACСАСТСТСТСТСТTTTTGATTGA-3' \\
\hline ACADS & 5'-GCTGCCATGCTGAAGGATAA-3' & 5'-GGCATCTCTGTCACGTAGCC-3' \\
\hline ATM & 5'-TGGATCCAGCTATTTGGTTTGA-3' & 5'-CCAAGTATGTAACCAACAATAGAAGAAGTAG-3' \\
\hline BAG1 & 5'-CACAGCAATGAGAAGCACG-3' & 5'-GTGTTTCCATTTCCTTCAGAG-3' \\
\hline BAG3 & 5'-ATGACCCATCGAGAAACTGC-3' & 5'-AATTGGGATGTGTCCAGGAG-3' \\
\hline CIRBP & 5'-GAGGGCTGAGTTTTGACACC-3' & 5'-TGGGTCTCCCTGTCTTTCAC-3' \\
\hline CYP19A1 & 5'-CAAGGTTATTTTGATGCATGG-3' & 5'-AATCCTTGACAGACTTCTCAT-3' \\
\hline DEGS1 & 5'-TTGAGGGCTGGTTCTTCTGT-3' & 5'-AATTGGTTTGGGGTTGATGA-3' \\
\hline ESR1 & $5^{\prime}$-GTGTACAACTACCCCGAGGGC-3' & 5'-AAACCCCCCAGGCCGTTGGAG-3' \\
\hline EVL & 5'-TTCCGTGATGGTCTACGATG-3' & 5'-GCTGGCAGTGTTGTGGTAGA-3' \\
\hline HMGB3 & 5'-TCAGCAGCCTTCCAAGGTAT-3' & 5'-CATTTGGCCCCACAAAATAG-3' \\
\hline KIAA1324 & 5'-AACACCCACTGCTGGAAATC-3' & 5'-GTTTGAGGCAAGCAGAAAGG-3' \\
\hline KRT18 & 5'-TGAGACGTACAGTCCAGTCCTT-3' & 5'-GCTCCATCTGTAGGGCGTAG-3' \\
\hline MAPK3 & 5'-TGCTGAACTCCAAGGGCTAT-3' & 5'-TAGTGCTTGCCAGGGAAGAT-3' \\
\hline MUC1 & 5'-GTGCCCCCTAGCAGTACCG-3' & 5'-GACGTGCCCCTACAAGTTGG-3' \\
\hline MX1 & 5'-AGCTCGGCAACAGACTCTTC-3' & 5'-GGATGATCAAAGGGATGTGG-3' \\
\hline PGR & 5'-CGCGCTCTACCCTGCACTC-3' & 5'-TGAATCCGGCCTCAGGTAGTT-3' \\
\hline PSMD7 & 5'-GAATGACATTGCCATCAACG-3' & 5'-GTAGGCAGCCCTAGGTCCTT-3' \\
\hline TP53 & 5'-GCGCACAGAGGAAGAGAATC-3' & 5'-AGAGGAGCTGGTGTTGTTGG-3' \\
\hline $18 S$ & 5'-GTCTGTGATGCCCTTAGATG-3' & 5'-AGCTTATGACCCGCACTTAC-3' \\
\hline
\end{tabular}

and $60{ }^{\circ} \mathrm{C}$ for $1 \mathrm{~min}$. Relative levels of gene expression were calculated by target gene levels normalized to the endogenously expressed housekeeping gene (18S rRNA). The second derivative maximum method was used to determine the crossing point $(\mathrm{Cp})$ for each sample (realized in triplicate). The mean value was used to calculate the $\Delta \mathrm{Cp}$ ( $\mathrm{Cp}$ of the target gene minus $\mathrm{Cp}$ of the $18 \mathrm{~S}$ gene). Gene expression levels were obtained according to the transformation $\left(2^{-\Delta \mathrm{Cp}}\right)$. Results were expressed as the mean \pm s.E.M. of five independent experiments.

To confirm the identity of adiponectin, leptin, AdipoR1, AdipoR2, Ob-Rt, and Ob-R1 PCR products, the PCR products were sequenced in both directions using the same primers as described above for amplification and a DNA dye terminator cycle sequencing kit (Applied Biosytems, Courtaboeuf, France). Sequence analysis was performed on an Applied Biosystems model 377 DNA Sequencer.

\section{Statistical analysis}

Statistical analysis was performed using the $\chi^{2}$ test for the immunohistochemical procedure and paired Student's $t$-test for in vitro experiments. A $P$ value of $<0.05$ (flagged as *) was considered as statistically significant, whereas $P<0.1$ (flagged as \#) was considered as a trend.

\section{Results}

\section{Expression of AdipoR1, AdipoR2, and Ob-Rt in breast tissue}

AdipoR1, AdipoR2, and Ob-Rt were detected by immunohistochemical analysis in the cytoplasm of invasive ductal cancer cells and adjacent normal cells (Table 2A). AdipoR1 expression was positive in 18\% (8 out of 45) of breast cancer tissues and 8\% (3 out of 40) of normal adjacent tissues (Fig. 1A and D). AdipoR1 appeared to be induced in breast cancer tissue versus normal tissue, but the difference was not statistically significant ( $\chi^{2}$ test, $P=0.16$ ). AdipoR2 expression was more pronounced in malignant cells than normal tissue, since AdipoR2 was detected in $82 \%$ (37 out of 45) of tumours but in only 53\% (21 out of 40) of healthy tissue ( $\chi^{2}$ test, $P<0.01$; Fig. 1B and E). Ob-Rt protein was detected in 38 out of the $45(84 \%)$ invasive ductal tissues and in 29 out of the $40(73 \%)$ normal adjacent tissues studied, without significant difference between the two tissues ( $\chi^{2}$ test, $P=0.18$; Fig. $1 \mathrm{C}$ and $\mathrm{F}$ ). 


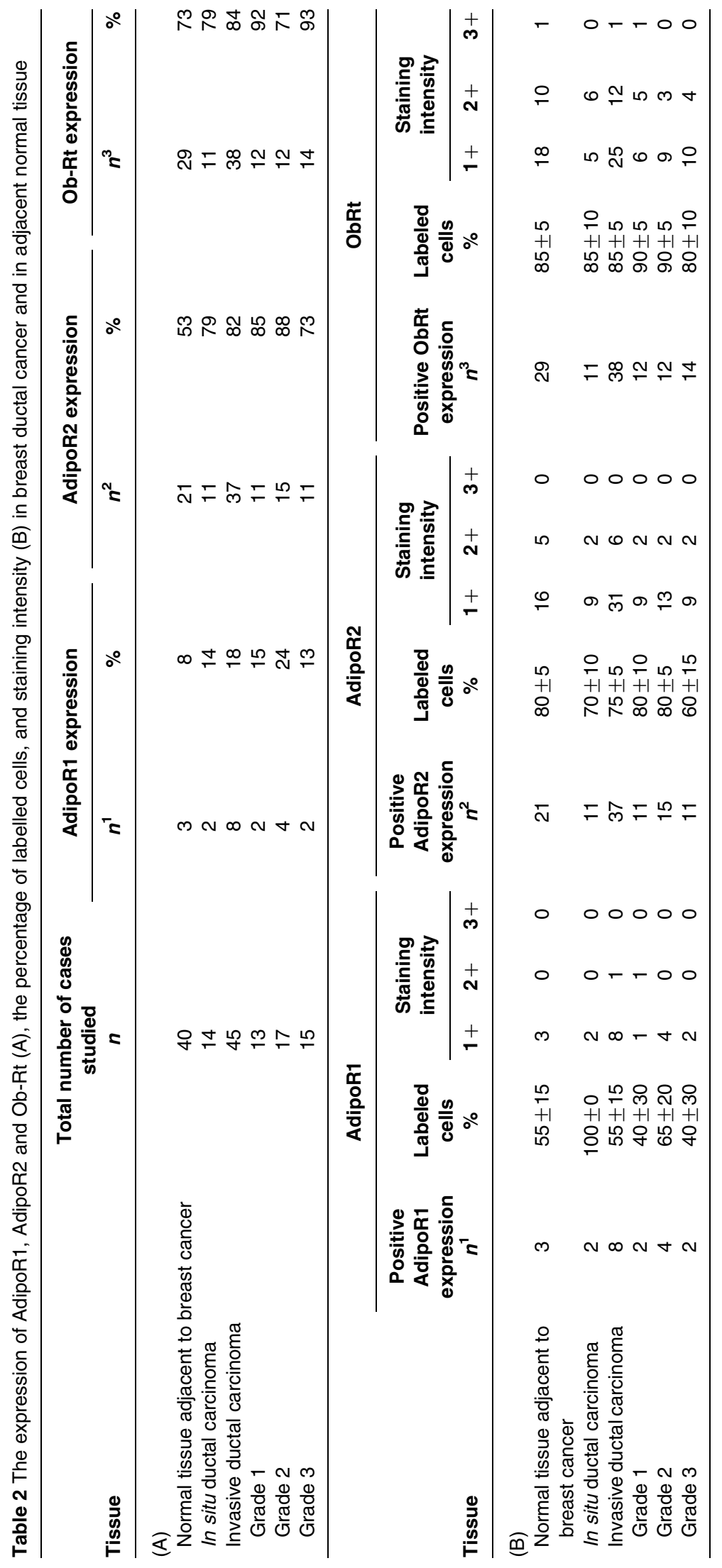



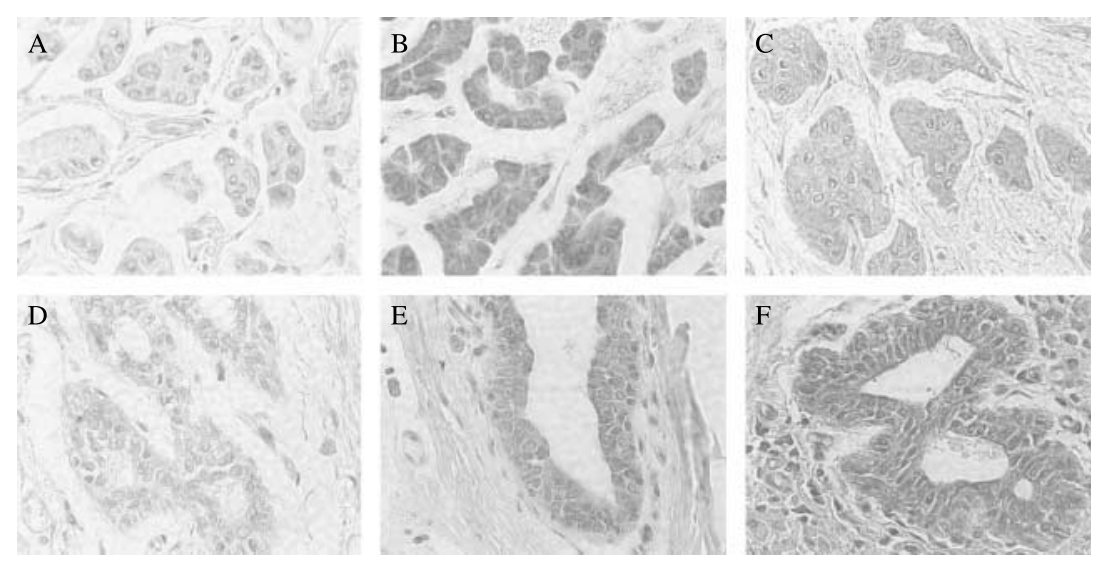

Figure 1 Immunohistochemical detection of AdipoR1, AdipoR2 and Ob-Rt in breast tissue. Invasive ductal cancer cells express AdipoR1 (A), AdipoR2 (B) and Ob-Rt (C). Healthy adjacent tissue presents immunopositivity for AdipoR1 (D), AdipoR2 (E) and Ob-Rt (F).

The in situ ductal carcinoma showed low expression of AdipoR1 (14\% of cases studied) and high expression of AdipoR2 and Ob-Rt (79\% of cases studied; Table 2A).

Finally, in cases expressing AdipoR1, AdipoR2, or Ob-Rt, the percentage of labeled cells and staining intensity were similar between invasive ductal carcinoma and adjacent normal tissue (Table 2B).

\section{Expression of adiponectin, leptin, and their receptors in MCF-7 breast cancer cells}

The mRNA of adiponectin, leptin, and their receptors was detected in MCF-7 cancer cells (Fig. 2A). Interestingly, leptin expression was radically higher (35-fold) than adiponectin expression. In addition, AdipoR1 expression was 15-fold higher than AdipoR2 expression. Ob-Rt expression was sevenfold higher than the expression of the full-length isoform Ob-Rl. Finally, AdipoR1 and AdipoR2 were highly significantly more expressed than Ob-Rt (120- and 8-fold higher expression respectively) and Ob-Rl (849- and 58 -fold higher expression respectively; $t$-test, $P<0.01)$.

Immunohistochemical staining detected adiponectin, leptin, and their receptors in the cytoplasm of MCF-7 breast cancer cells (Fig. 2B).

\section{Effect of adiponectin, leptin, or both adipokines on breast cancer cell proliferation}

Adiponectin $(10 \mu \mathrm{g} / \mathrm{ml})$ significantly decreased the proliferation of MCF-7 cells by 11.1, 11.2, 14.4, and $15.6 \%$ at $24,48,72$, and $96 \mathrm{~h}$ respectively versus controls ( $t$-test, $P<0.05$; Fig. 3 A). At $1 \mu \mathrm{g} / \mathrm{ml}$, adiponectin significantly inhibited cellular growth by
7.8 and $7.6 \%$ at 72 and $96 \mathrm{~h}$ respectively versus controls ( $t$-test, $P<0.05)$. Moreover, the effect of adiponectin at $10 \mu \mathrm{g} / \mathrm{ml}$ was significantly more pronounced at all time points analysed compared with the effects of $1 \mu \mathrm{g} / \mathrm{ml}$ ( $t$-test, $P<0.05$ ), whereas $0.1 \mu \mathrm{g} / \mathrm{ml}$ had no effect.

Leptin at $1 \mu \mathrm{g} / \mathrm{ml}$ enhanced the growth of MCF-7 breast cancer cells by $10.5,13.4$, and $16.3 \%$ at 48,72 , and $96 \mathrm{~h}$ respectively versus controls $(t$-test, $P<0.05$; Fig. 3B). The lower leptin concentrations $(0.01$ and $0.1 \mu \mathrm{g} / \mathrm{ml}$ ) were inefficient in reducing cell proliferation.

Interestingly, adiponectin at $1 \mu \mathrm{g} / \mathrm{ml}$ significantly inhibited leptin-stimulated breast cancer cell proliferation at 48, 72, and $96 \mathrm{~h}$ versus controls ( $t$-test, $P<0.05$; Fig. 3C).

\section{Interaction of adiponectin and leptin pathways}

These studies were performed using the most efficient concentrations of adiponectin $(10 \mu \mathrm{g} / \mathrm{ml})$ and leptin $(1 \mu \mathrm{g} / \mathrm{ml})$ on MCF-7 cancer cells that were incubated for $96 \mathrm{~h}$ (Fig. 4). Adiponectin significantly upregulated (88\% induction) adiponectin mRNA and downregulated $(-26 \%)$ Ob-Rt mRNA expression. In addition, adiponectin tended to downregulate leptin $(-36 \%)$ and $\mathrm{Ob}-\mathrm{Rl}(-28 \%)$ expression. Adiponectin treatment had no effect on AdipoR1 and AdipoR2 mRNA abundance.

Leptin significantly upregulated $(+30 \%)$ Ob-Rl mRNA and downregulated $(-23 \%)$ AdipoR1 mRNA expression. Leptin treatment also tended to induce leptin mRNA expression $(+31 \%)$. Leptin had no effect on the expression of adiponectin, AdipoR2, or Ob-Rt mRNA. 

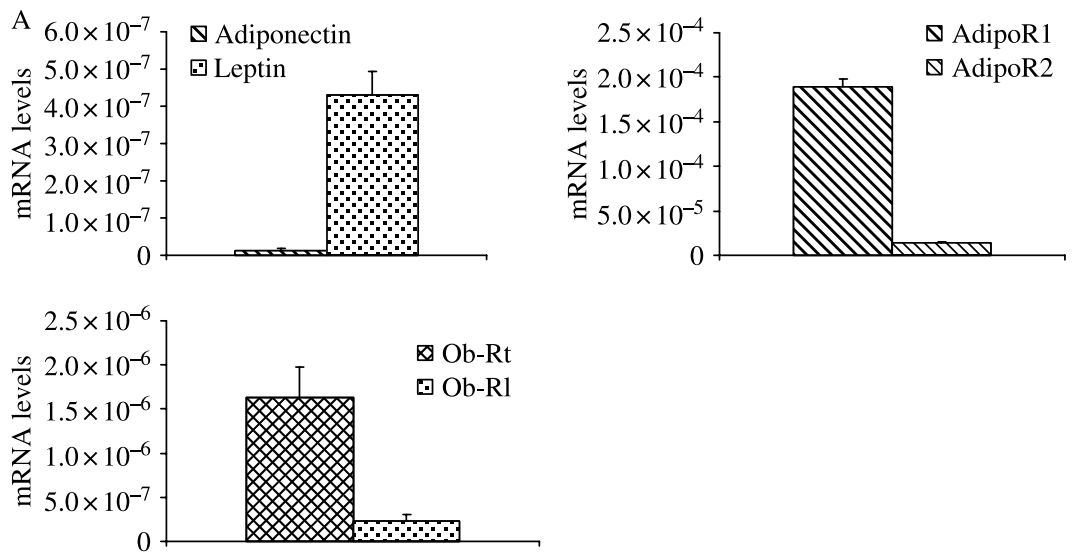

B
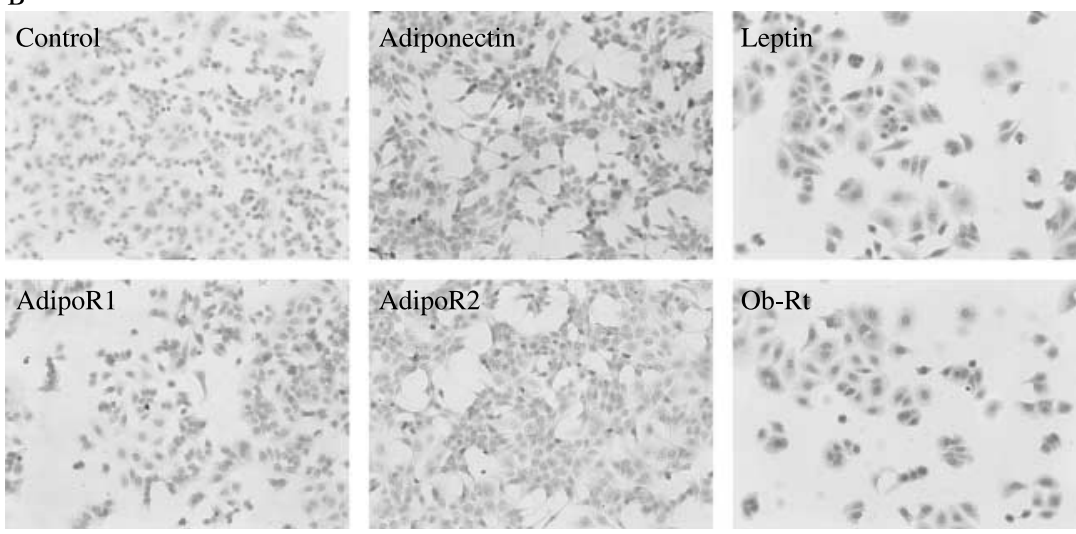

Figure 2 Expression of adiponectin, leptin and their specific receptors in MCF-7 breast cancer cells. The expression of adiponectin, leptin and their receptors was analysed by quantitative RT-PCR as described in Materials and Methods (A). Bars are the means \pm S.E.M. obtained from five independent experiments. The protein expression of adiponectin, leptin and their receptors was investigated by immunohistochemistry $(B)$.

\section{Effect of adipokines on gene expression}

We used microarray analysis to explore the effects of adiponectin and leptin on numerous pathways involved in breast cancer development. Table 3 summarizes the genes showing significant differences $(P<0.05)$ or statistical trends $(P<0.1)$ versus controls. We identified 15 genes that were altered by adiponectin treatment and 3 genes that were modified by leptin incubation. These results were confirmed by qRT-PCR (Fig. 5).

\section{Discussion}

Obesity is an established risk factor for breast cancer in postmenopausal women (Chu et al. 1991, Lahmann et al. 2004). This study provides evidence that adiponectin and leptin, which are both adipocytesecreted hormones that are deregulated in obesity, may be involved in breast cancer development.
Using an immunohistochemical approach, we detected AdipoR1, AdipoR2, and Ob-Rt in breast cancer tissue and in normal tissue adjacent to malignant lesions. However, AdipoR2 and Ob-Rt were expressed in more than $80 \%$ of breast cancer tissues studied, in contrast with AdipoR1 that was found in only $18 \%$ of cancer tissues. Korner et al. (2007) recently have investigated adiponectin receptor expression in breast cancer biopsies and showed that AdipoR1 and AdipoR2 were expressed in about 30\% of cancer tissues studied. Our study suggests that AdipoR2 may be the effective receptor for in vivo adiponectin signaling in cancer tissue. However, this notion remains uncertain, since other studies obtained conflicting results. Nakayama et al. (2007) noted that siRNA against AdipoR1 completely abrogated the growth inhibition of adiponectin in T47D cells, and limited the anti-proliferative activity of adiponectin in MDA-MB-231 cells to about 50\%. In contrast, two studies reported that siRNA against AdipoR1, 

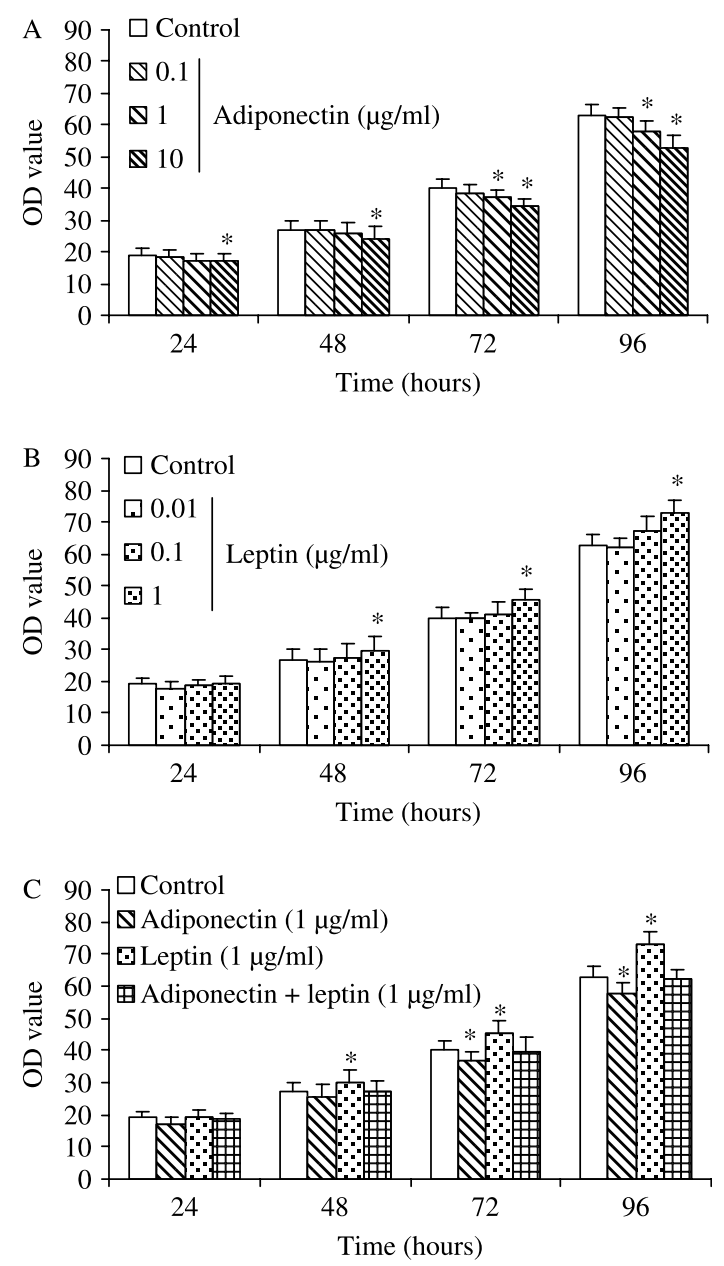

Figure 3 Effect of adiponectin, leptin and both adipokines on MCF-7 breast cancer cell proliferation. Breast cancer cells were exposed to adiponectin (A), leptin (B) or both adipokines (C) for the times indicated. Bars are the means \pm S.E.M. obtained from five determinations. *Significant difference compared to control $(P<0.05$, $t$-test $)$.

AdipoR2, or both had no effect on adiponectinmediated inhibition of the proliferation in MDA-MB231 cells (Wang et al. 2006, Dos Santos et al. 2008).

We also observed that AdipoR2 expression was higher in breast cancer tissue than in normal adjacent tissue. A recent study has reported higher levels of adiponectin receptors in colorectal carcinomas versus nontumor specimens (Williams et al. 2008). In another investigation, AdipoR1 expression tended to be more pronounced in breast malignant cells than normal tissue (Korner et al. 2007). The relevance of these observations is still unclear, but may indicate an upregulation of adiponectin receptors in carcinogenesis.

In the current study, adiponectin mRNA and protein were identified in MCF-7 breast cancer cells for the first time, whereas Takahata et al. (2007) did not observe adiponectin mRNA expression in breast cancer cell lines. Interestingly, leptin mRNA expression in MCF-7 cells was dramatically higher (34.7-fold) than adiponectin mRNA expression. This finding is in accordance with our previous immunohistochemical study, where adiponectin-positive staining was noted in $15 \%$ of the 45 breast cancer tissues studied and leptin-positive staining was observed in $80 \%$ of the 45 breast cancer tissues (Jarde et al. 2008b). These results suggest that leptin is much more abundant in the local breast cancer environment than adiponectin. As previously described (Dieudonne et al. 2002, Nakayama et al. 2007), adiponectin and leptin receptors were identified in the MCF-7 cells, with the latter being significantly lower. Interestingly, we noted that adiponectin induced adiponectin mRNA $(P<0.05)$ and that leptin increased leptin $(P<0.1)$ and Ob-Rl $(P<0.05)$ mRNA expression in MCF-7 cells. Chen et al. (2006a) also reported that leptin treatment induced leptin and Ob-Rl mRNA expression in ZR-75-1 breast cancer cells. Thus, these adipokines may autoregulate their pathways to amplify the signal. Moreover, in the present study, adiponectin downregulated the leptin pathway by decreasing leptin, $\mathrm{Ob}-\mathrm{Rt}$, and $\mathrm{Ob}-\mathrm{R} 1 \mathrm{mRNA}$ expression in MCF-7 cancer cells. Similarly, AdipoR1 mRNA expression was reduced by leptin treatment, a finding that is similar to a recent study where leptin treatment decreased AdipoR1 and AdipoR2 mRNA expression in MDAMB-231 cells (Dos Santos et al. 2008).

Therefore, these adipokines appear to exert antagonistic activities by downregulating each other's signaling pathway. These results are particularly important where obese women are concerned, since hyperleptinemia can decrease the sensitivity of cancer cells to adiponectin via downregulation of AdipoR1

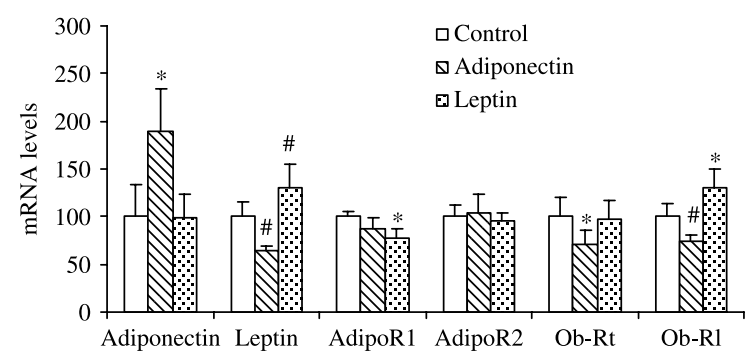

Figure 4 Effect of adiponectin and leptin on their own pathways. MCF-7 breast cancer cells were exposed to adiponectin $(10 \mu \mathrm{g} / \mathrm{ml})$ or leptin $(1 \mu \mathrm{g} / \mathrm{ml})$ for $96 \mathrm{~h}$. The expression of adiponectin, leptin and their receptors was analysed by quantitative RT-PCR as described in Materials and methods. Bars are the means \pm S.E.M. obtained from five determinations. *Significant difference compared to control $(P<0.05, t$-test $)$, \#Statistical trend compared to control $(P<0.1, t$-test). 


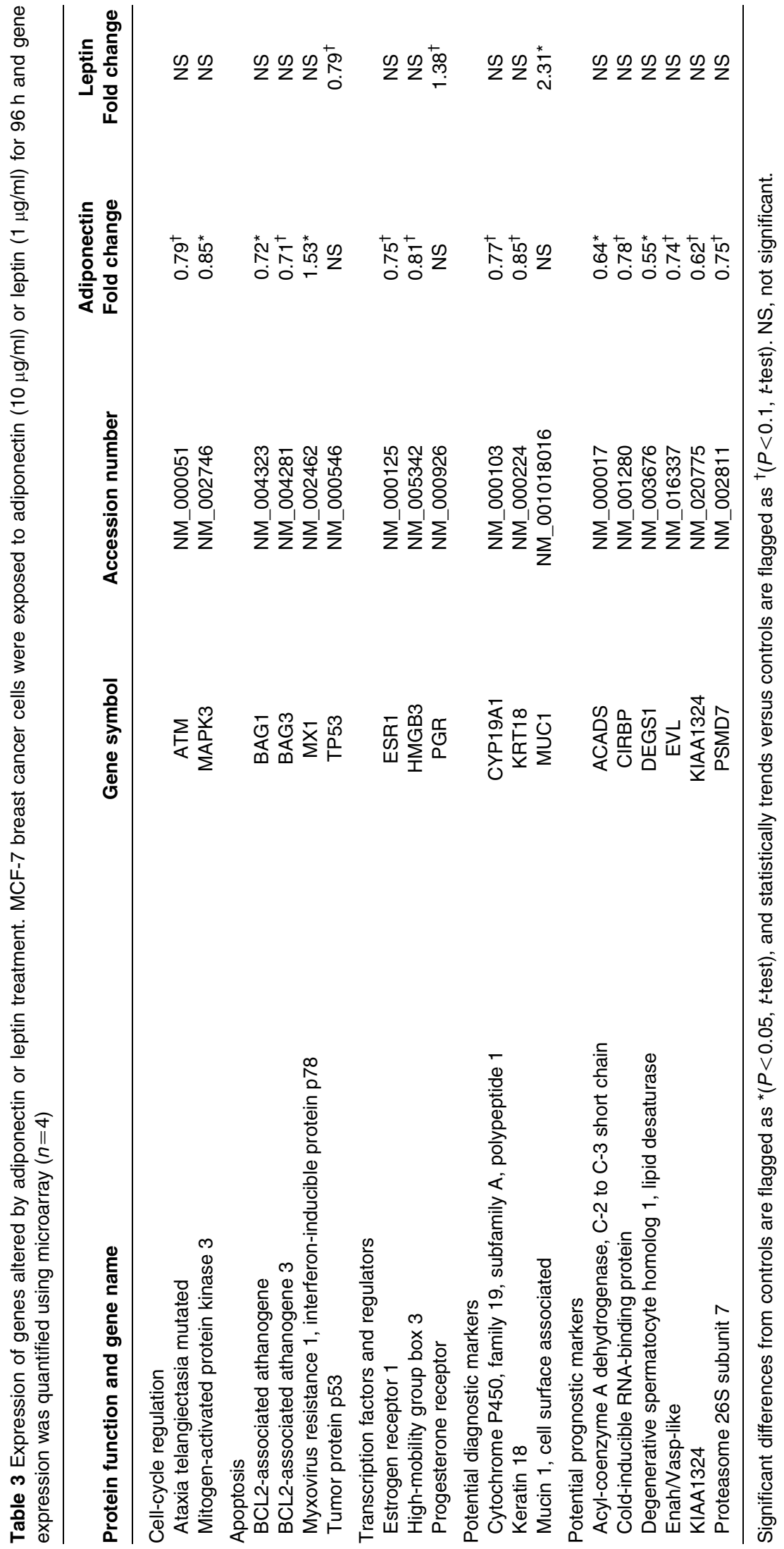




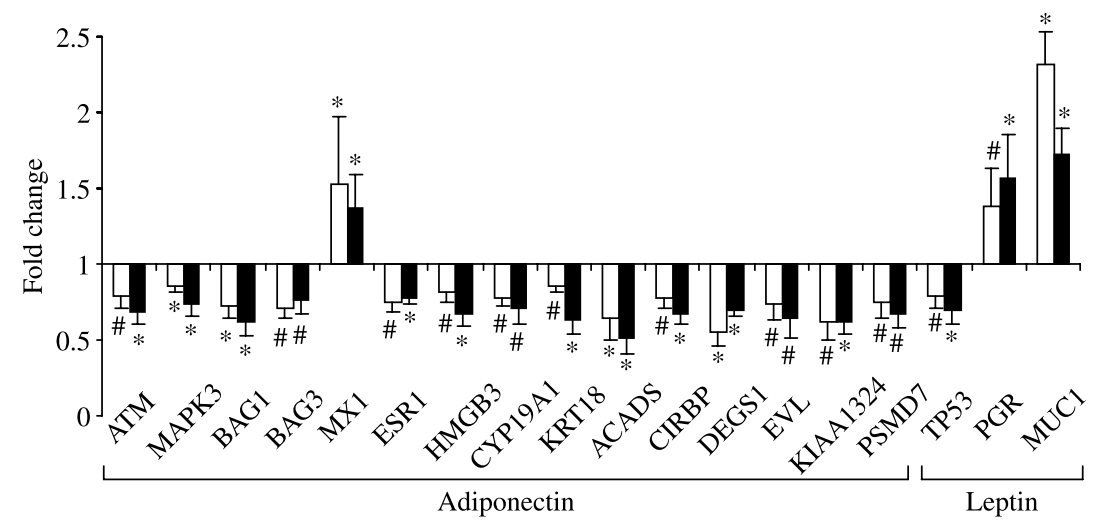

Figure 5 qRT-PCR validation of candidate genes. Data obtained from microarray experiments (open bars) and qRT-PCR analysis (solid bars) are shown. *Significant difference compared to control $(P<0.05, t$-test), \#Statistical trend compared to control $(P<0.1, t$-test).

and upregulation of the leptin pathway. Furthermore, obesity-associated hypoadiponectinemia may limit the negative feedback of adiponectin on leptin signaling in cancer cells.

We also found that adiponectin inhibited the growth of MCF-7 breast cancer cells, whereas leptin induced a proliferative response. Similar results have been observed in previous studies using MCF-7, MDAMB-231, SK-BR-3, and T47D breast cancer cells (Kang et al. 2005, Dieudonne et al. 2006, Nakayama et al. 2007). We also noted that adiponectin inhibited the proliferative activity of leptin, which underlines the antagonistic activity of these adipokines in breast cancer. Similar results were obtained in preneoplastic colon epithelial cells (Fenton et al. 2008).

To determine the potential pathways involved in the regulation of cell proliferation by these adipokines, we evaluated the effect of adiponectin and leptin on numerous molecular markers of breast cancer using microarray and qRT-PCR analysis. Although an induction of CYP19A1 (aromatase), an enzymecatalyzing estrogen biosynthesis, and the activation of estrogen receptor- $\alpha$ (ESR1) in MCF-7 cancer cells (Catalano et al. 2003, 2004) by leptin were recently described, the mRNA expression of this enzyme was not altered by leptin in the current study. However, we observed that adiponectin downregulated ER $\alpha$ mRNA and tended to downregulate aromatase mRNA. Recently, Treeck et al. (2008) have showed that adiponectin increased the mRNA expression of ER $\beta 5$ in MCF-7 cells, a protein known to negatively interfere with the transcriptional activity of ER $\alpha$. These results suggest a potential anti-proliferative role of adiponectin in breast cancer, mediated by the decreased in situ estradiol production and decreased sensitivity of cancer cells. We also observed that leptin induced progesterone receptor mRNA expression in MCF-7 cells. The relationship between progesterone and leptin is unclear, but an interaction between these two pathways is possible, since progesterone-induced inhibition of Ob-Rl mRNA has been described in human endometrium (Koshiba et al. 2001).

Mitogen-activated protein kinase 3 (MAPK3) belongs to the family of signal transduction intermediates leading to cell proliferation and is suppressed by adiponectin. Overexpression of MAPK has been observed in breast cancer and metastatic cells (Sivaraman et al. 1997). Recently, Dieudonne et al. (2006) have observed that adiponectin inhibited MAPK phosphorylation in MCF-7 cells. These results suggest that inhibition of MAPK3 expression and/or phosphorylation may be one of the numerous factors explaining the anti-proliferative activity of adiponectin in cancer cells. The physiological role of adiponectinmediated inhibition of the ATM pathway remains unclear, because this protein induces the activation of cell-cycle checkpoints and the initiation of DNA repair, and may lead to the induction of apoptosis (Prokopcova et al. 2007).

In addition, adiponectin may be involved in the induction of apoptosis by downregulating BAG1, an anti-apoptotic factor, and upregulating MX1 mRNA, a gene engaged in the induction of apoptosis. However, the relationship between adiponectin and the initiation of apoptosis has not been clearly established, and numerous studies have obtained conflicting results. Three recent studies have failed to detect apoptosis in adiponectin-incubated MCF-7, MDA-MB-231, 
and T47D cells (Wang et al. 2006, Arditi et al. 2007, Nakayama et al. 2007), whereas other studies demonstrated a stimulating effect in MCF-7 and MDA-MB-231 cells (Kang et al. 2005, Dieudonne et al. 2006, Wang et al. 2006). Furthermore, Grossmann et al. noted that adiponectin activated caspase-8 and PARP in MCF-7 cells (Grossmann et al. 2008). Focusing on leptin, we noted that the expression of TP53, an apoptosis-inducible factor, was decreased by leptin treatment. Similar results were obtained in ZR-75-1 breast cancer cells (Chen et al. 2006a). This suggests that leptin may stimulate cell proliferation via downregulation of apoptosis in breast cancer cells.

Adipokines may interact with potential diagnosis markers in MCF-7 cells. KRT18 is a gene encoding for keratin 18 components of the intermediate filaments of the cytoskeleton. Overexpression of KRT18 abrogated the ability of MDA-MB-231 to form tumors and metastasize in athymic mice (Buhler \& Schaller 2005). In addition, reducing the expression of KRT18 increased the aggressiveness of breast cancer cell lines. Adiponectin downregulated KRT18 mRNA, and this result suggests that adiponectin may not only be considered as an anti-proliferative factor. Moreover, the treatment of MCF-7 cancer cells with leptin induced the expression of another diagnostic marker gene, MUC1. MUC1 expression is related to the aggressive behavior of human neoplasm and to poor patient outcome (Yonezawa et al. 2008). MUC1 may function as an anti-adhesion molecule enabling invasion into surrounding tissues (Yonezawa et al. 2008).

The present study also provides evidence for an interaction between adiponectin and potential prognostic markers. ACADS proteins are a family of mitochondrial enzymes catalyzing the initial rate-limiting step in the $\beta$-oxidation of fatty acylCoA. Numerous genes associated with fatty acid metabolism, including ACADS, were upregulated in colorectal cancer versus healthy tissue (Yeh et al. 2006), suggesting that ACADS are involved in carcinogenesis. Moreover, the partial loss of the prognostic marker DEGS1, an enzyme that catalyzes the desaturation of dihydroceramide into ceramide, induced an accumulation of dihydroceramide and led to the inhibition of proliferation with cell-cycle arrest in human neuroblastoma cells (Kraveka et al. 2007). In our conditions, adiponectin significantly decreased ACADS and DEGS1 mRNA expression in MCF-7 cancer cells. There appears to be a close relationship between adiponectin and fatty acids that may at least partially explain the anti-proliferative effect of this adipokine in cancer cells.

Finally, we noted that adiponectin significantly decreased the expression of KIAA1324 mRNA and tended to decrease EVL mRNA expression in MCF-7 cells. KIAA1324, an estrogen-induced gene, is overexpressed in MCF-7 cells compared with nonmalignant cell lines (Bauer et al. 2004). EVL, which belongs to the enabled/vasodilator-stimulated phosphoprotein family, regulates the actin cytoskeleton. Upregulation of EVL correlates positively with the clinical stages of breast cancer (Hu et al. 2008). In addition, overexpression of EVL promoted the motility of MCF-7 cells (Hu et al. 2008).

In our study, the effects of these adipokines on cell proliferation and gene expression were modest. However, it is important to note that obesity is associated with both hypoadiponectinemia and hyperleptinemia, which suggests a cumulative effect on breast cancer cell growth via proliferative effects of leptin and a decreased anti-proliferative activity of adiponectin. During breast carcinogenesis, the slightly elevated proliferation capacity explained by the dysregulation of adiponectin and leptin in obesity may be highly relevant. These adipokines also alter gene expression of various proteins relevant in breast cancer development.

In conclusion, this study identified new gene targets of adiponectin that may be relevant for the diagnosis and/or therapy of breast cancer.

\section{Declaration of interest}

The authors declare that there is no conflict of interest that could be perceived as prejudicing the impartiality of the research reported.

\section{Funding}

This work received financial support from the local office of the French Anti-Cancer League (Ligue Contre le Cancer du Puy-de-Dôme). The study was supported by a grant from the Deutsche Forschungsgemeinschaft (BU 1141/3-2). Thierry Jardé was awarded a fellowship from the French Ministry of Research and Technology.

\section{Acknowledgements}

The authors thank Prof. C Forestier (Laboratoire de Bactériologie, UFR Pharmacie, Clermont-Ferrand, France) and Prof. G Picard (Laboratoire de Génétique des Eucaryotes et Endocrinologie Moléculaire, Université Blaise Pascal, Clermont-Ferrand, France) for their expert assistance. 


\section{References}

Arditi JD, Venihaki M, Karalis KP \& Chrousos GP 2007 Antiproliferative effect of adiponectin on MCF7 breast cancer cells: a potential hormonal link between obesity and cancer. Hormone and Metabolic Research 39 9-13.

Arita Y, Kihara S, Ouchi N, Takahashi M, Maeda K, Miyagawa J, Hotta K, Shimomura I, Nakamura T, Miyaoka K et al. 1999 Paradoxical decrease of an adipose-specific protein, adiponectin, in obesity. Biochemical and Biophysical Research Communications 257 79-83.

Bauer M, Aust G \& Schumacher U 2004 Different transcriptional expression of KIAA1324 and its splicing variants in human carcinoma cell lines with different metastatic capacity. Oncology Reports 11 677-680.

Buhler H \& Schaller G 2005 Transfection of keratin 18 gene in human breast cancer cells causes induction of adhesion proteins and dramatic regression of malignancy in vitro and in vivo. Molecular Cancer Research 3 365-371.

Caldefie-Chezet F, Poulin A \& Vasson MP 2003 Leptin regulates functional capacities of polymorphonuclear neutrophils. Free Radical Research 37 809-814.

Caldefie-Chezet F, Damez M, de Latour M, Konska G, Mishellani F, Fusillier C, Guerry M, Penault-Llorca F, Guillot J \& Vasson MP 2005 Leptin: a proliferative factor for breast cancer? Study on human ductal carcinoma Biochemical and Biophysical Research Communications 334 737-741.

Catalano S, Marsico S, Giordano C, Mauro L, Rizza P, Panno ML \& Ando S 2003 Leptin enhances, via AP-1, expression of aromatase in the MCF-7 cell line. Journal of Biological Chemistry 278 28668-28676.

Catalano S, Mauro L, Marsico S, Giordano C, Rizza P, Rago V, Montanaro D, Maggiolini M, Panno ML \& Ando S 2004 Leptin induces, via ERK1/ERK2 signal, functional activation of estrogen receptor alpha in MCF-7 cells. Journal of Biological Chemistry 279 19908-19915.

Chen C, Chang YC, Liu CL, Chang KJ \& Guo IC $2006 a$ Leptin-induced growth of human ZR-75-1 breast cancer cells is associated with up-regulation of cyclin D1 and c-Myc and down-regulation of tumor suppressor p53 and p21WAF1/CIP1. Breast Cancer Research and Treatment 98 121-132.

Chen DC, Chung YF, Yeh YT, Chaung HC, Kuo FC, Fu OY, Chen HY, Hou MF \& Yuan SS 2006 b Serum adiponectin and leptin levels in Taiwanese breast cancer patients. Cancer Letters 237 109-114.

Chu SY, Lee NC, Wingo PA, Senie RT, Greenberg RS \& Peterson HB 1991 The relationship between body mass and breast cancer among women enrolled in the Cancer and Steroid Hormone Study. Journal of Clinical Epidemiology 44 1197-1206.

Debiton E, Madelmont JC, Legault J \& Barthomeuf C 2003 Sanguinarine-induced apoptosis is associated with an early and severe cellular glutathione depletion. Cancer Chemotherapy and Pharmacology 51 474-482.
De Vos P, Saladin R, Auwerx J \& Staels B 1995 Induction of ob gene expression by corticosteroids is accompanied by body weight loss and reduced food intake. Journal of Biological Chemistry 270 15958-15961.

Dieudonne MN, Machinal-Quelin F, Serazin-Leroy V, Leneveu MC, Pecquery R \& Giudicelli Y 2002 Leptin mediates a proliferative response in human MCF7 breast cancer cells. Biochemical and Biophysical Research Communications 293 622-628.

Dieudonne MN, Bussiere M, Dos Santos E, Leneveu MC, Giudicelli Y \& Pecquery R 2006 Adiponectin mediates antiproliferative and apoptotic responses in human MCF7 breast cancer cells. Biochemical and Biophysical Research Communications 345 271-279.

Dos Santos E, Benaitreau D, Dieudonne MN, Leneveu MC, Serazin V, Giudicelli Y \& Pecquery R 2008 Adiponectin mediates an antiproliferative response in human MDA-MB 231 breast cancer cells. Oncology Reports 20 971-977.

Elston CW \& Ellis IO 1991 Pathological prognostic factors in breast cancer. I. The value of histological grade in breast cancer: experience from a large study with long-term follow-up. Histopathology 19 403-410.

Fenton JI, Birmingham JM, Hursting SD \& Hord NG 2008 Adiponectin blocks multiple signaling cascades associated with leptin-induced cell proliferation in Apc $\mathrm{Min} /+$ colon epithelial cells. International Journal of Cancer 122 2437-2445.

Goncalves-Mendes N, Blanchon L, Meiniel A, Dastugue B \& Sapin V 2004 Placental expression of SCO-spondin during mouse and human development. Gene Expression Patterns 4 309-314.

Grossmann ME, Nkhata KJ, Mizuno NK, Ray A \& Cleary MP 2008 Effects of adiponectin on breast cancer cell growth and signaling. British Journal of Cancer 98 370-379.

Han C, Zhang HT, Du L, Liu X, Jing J, Zhao X, Yang X \& Tian B 2005 Serum levels of leptin, insulin, and lipids in relation to breast cancer in China. Endocrine 26 19-24.

Hu X, Juneja SC, Maihle NJ \& Cleary MP 2002 Leptin - a growth factor in normal and malignant breast cells and for normal mammary gland development. Journal of the National Cancer Institute 94 1704-1711.

$\mathrm{Hu}$ LD, Zou HF, Zhan SX \& Cao KM 2008 EVL (Ena/VASP-like) expression is up-regulated in human breast cancer and its relative expression level is correlated with clinical stages. Oncology Reports 19 1015-1020.

Jarde T, Caldefie-Chezet F, Damez M, Mishellany F, Penault-Llorca F, Guillot J \& Vasson MP 2008a Leptin and leptin receptor involvement in cancer development: a study on human primary breast carcinoma. Oncology Reports 19 905-911.

Jarde T, Caldefie-Chezet F, Damez M, Mishellany F, Perrone D, Penault-Llorca F, Guillot J \& Vasson MP $2008 b$ Adiponectin and leptin expression in primary 
ductal breast cancer and in adjacent healthy epithelial and myoepithelial tissue. Histopathology 53 484-487.

Kang JH, Lee YY, Yu BY, Yang BS, Cho KH, Yoon DK \& Roh YK 2005 Adiponectin induces growth arrest and apoptosis of MDA-MB-231 breast cancer cell. Archives of Pharmacological Research 28 1263-1269.

Kershaw EE \& Flier JS 2004 Adipose tissue as an endocrine organ. Journal of Clinical Endocrinology and Metabolism 89 2548-2556.

Klein S, Wadden T \& Sugerman HJ 2002 AGA technical review on obesity. Gastroenterology 123 882-932.

Korner A, Pazaitou-Panayiotou K, Kelesidis T, Kelesidis I, Williams CJ, Kaprara A, Bullen J, Neuwirth A, Tseleni S, Mitsiades N et al. 2007 Total and high-molecular-weight adiponectin in breast cancer: in vitro and in vivo studies. Journal of Clinical Endocrinology and Metabolism 92 1041-1048.

Koshiba H, Kitawaki J, Ishihara H, Kado N, Kusuki I, Tsukamoto K \& Honjo H 2001 Progesterone inhibition of functional leptin receptor mRNA expression in human endometrium. Molecular Human Reproduction 7 567-572.

Kraveka JM, Li L, Szulc ZM, Bielawski J, Ogretmen B, Hannun YA, Obeid LM \& Bielawska A 2007 Involvement of dihydroceramide desaturase in cell cycle progression in human neuroblastoma cells. Journal of Biological Chemistry 282 16718-16728.

Lago F, Dieguez C, Gomez-Reino J \& Gualillo O 2007 The emerging role of adipokines as mediators of inflammation and immune responses. Cytokine and Growth Factor Reviews 18 313-325.

Lahmann PH, Hoffmann K, Allen N, van Gils CH, Khaw KT, Tehard B, Berrino F, Tjonneland A, Bigaard J, Olsen A et al. 2004 Body size and breast cancer risk: findings from the European Prospective Investigation into Cancer And Nutrition (EPIC). International Journal of Cancer 111 762-771.

Le Corre L, Chalabi N, Delort L, Bignon YJ \& BernardGallon DJ 2006 Differential expression of genes induced by resveratrol in human breast cancer cell lines. Nutrition and Cancer 56 193-203.

Maeda K, Okubo K, Shimomura I, Funahashi T, Matsuzawa Y \& Matsubara K 1996 cDNA cloning and expression of a novel adipose specific collagen-like factor, apM1 (AdiPose most abundant gene transcript 1). Biochemical and Biophysical Research Communications 221 286-289.

Mantzoros C, Petridou E, Dessypris N, Chavelas C, Dalamaga M, Alexe DM, Papadiamantis Y, Markopoulos C, Spanos E, Chrousos G et al. 2004 Adiponectin and breast cancer risk. Journal of Clinical Endocrinology and Metabolism 89 1102-1107.

Matsubara M, Maruoka S \& Katayose S 2002 Inverse relationship between plasma adiponectin and leptin concentrations in normal-weight and obese women. European Journal of Endocrinology 147 173-180.

Mix H, Widjaja A, Jandl O, Cornberg M, Kaul A, Goke M, Beil W, Kuske M, Brabant G, Manns MP et al. 2000 Expression of leptin and leptin receptor isoforms in the human stomach. Gut 47 481-486.

Miyoshi Y, Funahashi T, Kihara S, Taguchi T, Tamaki Y, Matsuzawa Y \& Noguchi S 2003 Association of serum adiponectin levels with breast cancer risk. Clinical Cancer Research 9 5699-5704.

Mounzih K, Lu R \& Chehab FF 1997 Leptin treatment rescues the sterility of genetically obese ob/ob males. Endocrinology 138 1190-1193.

Nakayama S, Miyoshi Y, Ishihara H \& Noguchi S 2007 Growth-inhibitory effect of adiponectin via adiponectin receptor 1 on human breast cancer cells through inhibition of S-phase entry without inducing apoptosis. Breast Cancer Research and Treatment 112 405-410.

Neumeier M, Weigert J, Schaffler A, Wehrwein G, MullerLadner U, Scholmerich J, Wrede C \& Buechler C 2006 Different effects of adiponectin isoforms in human monocytic cells. Journal of Leukocyte Biology 79 803-808.

Prokopcova J, Kleibl Z, Banwell CM \& Pohlreich P 2007 The role of ATM in breast cancer development. Breast Cancer Research and Treatment 104 121-128.

Ray A, Nkhata KJ \& Cleary MP 2007 Effects of leptin on human breast cancer cell lines in relationship to estrogen receptor and HER2 status. International Journal of Oncology 30 1499-1509.

Ruhl CE \& Everhart JE 2001 Leptin concentrations in the United States: relations with demographic and anthropometric measures. American Journal of Clinical Nutrition 74 295-301.

Saxena NK, Vertino PM, Anania FA \& Sharma D 2007 Leptin-induced growth stimulation of breast cancer cells involves recruitment of histone acetyltransferases and mediator complex to CYCLIN D1 promoter via activation of Stat3. Journal of Biological Chemistry $\mathbf{2 8 2}$ 13316-13325.

Sivaraman VS, Wang H, Nuovo GJ \& Malbon CC 1997 Hyperexpression of mitogen-activated protein kinase in human breast cancer. Journal of Clinical Investigation 99 1478-1483.

Solberg R, Aas V, Thoresen GH, Kase ET, Drevon CA, Rustan AC \& Reseland JE 2005 Leptin expression in human primary skeletal muscle cells is reduced during differentiation. Journal of Cellular Biochemistry 96 89-96.

Takahata C, Miyoshi Y, Irahara N, Taguchi T, Tamaki Y \& Noguchi S 2007 Demonstration of adiponectin receptors 1 and 2 mRNA expression in human breast cancer cells. Cancer Letters 250 229-236.

Treeck O, Lattrich C, Juhasz-Boess I, Buchholz S, Pfeiler G \& Ortmann O 2008 Adiponectin differentially affects 
gene expression in human mammary epithelial and breast cancer cells. British Journal of Cancer 99 1246-1250.

Wang Y, Lam JB, Lam KS, Liu J, Lam MC, Hoo RL, Wu D, Cooper GJ \& Xu A 2006 Adiponectin modulates the glycogen synthase kinase- $3 \beta / \beta$-catenin signaling pathway and attenuates mammary tumorigenesis of MDA-MB-231 cells in nude mice. Cancer Research 66 11462-11470.

Williams CJ, Mitsiades N, Sozopoulos E, Hsi A, Wolk A, Nifli AP, Tseleni-Balafouta S \& Mantzoros CS 2008 Adiponectin receptor expression is elevated in colorectal carcinomas but not in gastrointestinal stromal tumors. Endocrine-Related Cancer 15 289-299.
Yeh CS, Wang JY, Cheng TL, Juan CH, Wu CH \& Lin SR 2006 Fatty acid metabolism pathway play an important role in carcinogenesis of human colorectal cancers by microarray-bioinformatics analysis. Cancer Letters $\mathbf{2 3 3}$ 297-308.

Yonezawa S, Goto M, Yamada N, Higashi M \& Nomoto M 2008 Expression profiles of MUC1, MUC2, and MUC4 mucins in human neoplasms and their relationship with biological behavior. Proteomics 8 3329-3341.

Zhang Y, Proenca R, Maffei M, Barone M, Leopold L \& Friedman JM 1994 Positional cloning of the mouse obese gene and its human homologue. Nature 372 425-432. 